\title{
Collaborative Innovation (or Not?!) When Product Performance Is Critical
}

\author{
Thomas A. Weber \\ École Polytechnique Fédérale de Lausanne \\ thomas.weber@epfl.ch
}

\begin{abstract}
Research and development $(R \& D)$ collaborations are horizontal agreements among firms to join forces in their inventive activities. As in the context of the recent COVID-19 global pandemic, such collaborations are often promoted with an argument of increased $R \& D$ productivity. In numerous contexts, especially when marginal production costs are low, such as for medications or for software, the consumers' surplus depends critically on the best-performing product available on the market, for-all else equal-this product will tend to take a dominant position. Using a simple two-stage model of innovation and subsequent product commercialization on a market with heterogeneous consumers, we show that a noncollaborative patent race with patent protection (for the best product) provides strong innovation incentives, leading to better performing products than a regime of noncollaborative research without patent protection or of collaborative research (with profit sharing).
\end{abstract}

\section{Introduction}

Collaborative research is en vogue, and has even become a public necessity. In the face of the recent COVID19 global pandemic governments called on industry to unite so as to produce a vaccine in the shortest possible timeframe. Clearly, in the case of an infectious disease with the potential to cripple the global economy, the quality of a vaccine the "great coronavirus collaboration" [9] may come up with is of utmost importance. Since when searching for alternatives the expected bestperformance alternative increases with the aggregate effort put into the venture, it is important that incentives are such that the economic agents participating in the research have maximal incentives to exert effort. Given that the cost of experimentation does not vary much as a function of R\&D participation (at least in the shortrun), our pursuit here is to track the economic incentives when experimentation occurs in a group or individually, by keeping in mind that the performance of the product is key for consumer surplus (at a given price).

\subsection{Literature}

The classical understanding by Schumpeter [20] is that a firm's role is to develop production methods to satisfy its consumers' demand. The neoclassical view of $R \& D$, as summarized by Nelson [17], purports that firms need to obtain intellectual property rights to be able to appropriate the benefits of their research, thus resulting in a winner-takes-all patent race 1 The supra-normal rents from successful inventions provide in turn strong incentives to invest in inventive activities 2 Since firms may for various reasons not be able to by themselves exploit many of the inventions they make [21], incentives arise for them to share or license their new technologies as part of what eventually becomes collaborative innovation ${ }^{3}$ Indeed, Allen [1] proposes that in addition to public institutions, private firms, and individual inventors, there is a fourth source of new inventions which he terms the "collective invention" that results from close contacts, voluntary disclosure, and imitation of work practices. Instead of unintended knowledge dissipation, these spillovers may be desirable, as they might reduce the collective experimentation cost. Collaborative innovation is therefore not an accidental byproduct, but rather operationalized intentionally, by means of cooperative $R \& D$ agreements or cross-licensing deals among

\footnotetext{
${ }^{1}$ See, e.g., Reinganum [18] for a summary of classical results on the dynamics of innovation competition.

${ }^{2}$ These investments may sometimes even exceed the socially optimal amount of R\&D expenditures; see Prop. 10 (i).

${ }^{3}$ Foray [11 Ch. 3] mentions further reasons for R\&D collaboration, such as cost sharing, avoidance of redundancies, economies of specialization, as well as the need for reducing uncertainties associated with modular subsystems—best accomplished across firm boundaries. In addition, especially small firms may benefit from knowledge complementarities that arise in physical proximity to other firms and institutions in the same geographical area [8], while other firms may overcome distance barriers by mobility and alliance formation [19].

${ }^{4}$ The logic advanced here is motivated by the cooperation that can arise in a repeated stage game (such as the Prisoner's Dilemma [2]), due to the folk theorem [12, 13]. Yet even in a one-time interaction, the Coase theorem points to the possibility of Pareto-optimal outcomes in the presence of complete information and well-defined property rights [6].
}

URI: https://hdl.handle.net/10125/71406

978-0-9981331-4-0

(CC BY-NC-ND 4.0) 
different firms that may be otherwise competing [14] $]_{4}^{4}$

Collaboration on innovation works particularly well with modular systems where design problems can be isolated and individual contributions integrated into the full system, thus allowing for economies of specialization [3]; see also footnote 3. There is empirical evidence that external collaboration incentives (as part of a government program) may induce improvements in innovative performance, for example, in Germany [7]. Finally, by extending the notion of research partners to users and other semi-interested parties, collaborative innovation takes on the meaning of "open innovation" (a term coined by Chesbrough [5]), arguably leading to a paradigm shift in the procurement of new ideas [4] and a "commercialization" of external resources [23] with its own processes and infrastructure [10].

\subsection{Research Question}

Standing on the shoulders of giants (represented by the extant literature), our goal in this paper is quite modest. Using a simple, and arguably neoclassical, model we ask whether collaborative research makes sense from the point of view of joint experimentation, without resorting to additional "out-of-the-box" qualitative arguments to justify cooperation (such as those in footnote 3). This echoes the critique by Mowery [15] voiced more than two decades ago, that despite a proliferation of research collaborations (in his analysis at the industry-university interface), only a moderate success is visible-a phenomenon that is driven at least in part by self-interest (e.g., universities' potentially over-emphasizing their participation in the intellectual property rights derived from joint innovations).

\subsection{Contribution}

As emphasized in neoclassical economics, the selfinterest of economic agents (in the absence of psychological biases and bounded rationality) is a reliable predictor for their behavior. The model for inventive activity we employ here is that of sequential search for the most beneficial alternative, in the spirit of Weitzman [22]. Firms need to address heterogeneous market needs and therefore compete on quality and price, whereby the top-performing product (in terms of its quality) may or may not be eligible for intellectual property protection. Our simple finding is that by and large, there are no economic incentives for collaborative innovation unless intellectual property regimes are weak and experimentation costs are neither too small nor too large. In particular, when the best technology can be independently evaluated as such and patented, research competition is "healthy" in the sense that it provides the strongest innovation incentives, which for large experimentation costs results in R\&D activity that falls short of the socially optimal levels of experimentation, yet is prone to exceed the latter when the cost of experimentation is small.

\subsection{Outline}

The remainder of this paper is organized as follows. Sec.2describes the basic setup of the two-period model, including sequential experimentation by firms in the innovation phase and their pricing decisions in the commercialization phase. We derive the equilibria in various noncooperative settings (with and without patent protection), as well as in a collaborative setting. In Sec. 3, we examine the social planner's most preferred outcome, which leads to a comparison of all regimes in Sec. 4 Finally, Sec.5 5 concludes.

\section{Model}

Consider two firms, 1 and 2, that at time $t=0$ ("innovation phase") can invest in conducting experiments. At time $t=1$, the firms set prices so as to sell their innovations to consumers with heterogeneous preferences ("commercialization phase"); see Fig. 1.

In the innovation phase, firm $i$ 's product quality $q_{i}$ is determined by the outcome of the best of $n_{i}$ experiments, for $i \in\{1,2\}$. The random outcomes of the experiments are independent and identically distributed (i.i.d.) uniformly on the (normalized) quality space $\mathcal{Q}=$ $[0,1]$. Higher outcomes indicate a better quality (e.g., in terms of treatment benefit for a cure, or performance for a durable good such as software). The cost of each experiment is $c>0$. An "experiment" consists of a discrete research and development (R\&D) effort, which could amount to a test configuration, a prototype, or any other costly effort that would determine the likely product quality in the event of commercialization 5

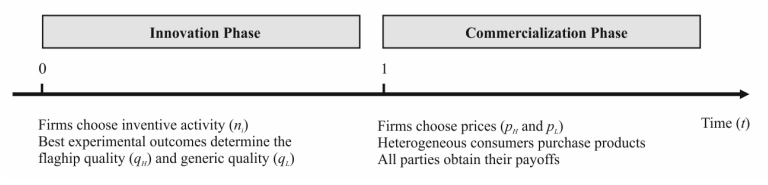

Figure 1: Timeline.

In the commercialization phase (i.e., at time $t=1$ ), the firms set prices so as to maximize their respective profits from selling the imperfectly substitutable products to a heterogeneous consumer base ${ }^{6}$ Each consumer

\footnotetext{
${ }^{5}$ The quality itself may be random, in which case $q_{i}$ represents the expected performance value.

${ }^{6}$ The products are imperfectly substitutable because their qualities (i.e., performance characteristics) are generically different. Indeed, the probability for the two firms' products to exhibit equivalent performance characteristics (i.e., $q_{1}=q_{2}$ ) is zero.

${ }^{7}$ In this widely used linear utility representation $u$, the consumer's type $\theta$ can be considered as his marginal utility for quality [16].
} 
of type $\theta$ has utility $u\left(p_{i}, q_{i} ; \theta\right)=\theta q_{i}-p_{i}$ if he buys a good of quality $q_{i}$ and price $p_{i}$, otherwise his utility is zero 7 Consumer types $\theta$ are uniformly distributed on the (normalized) type space $\Theta=[0,1]$, and the total number of consumers is normalized to one. Assume that the marginal cost of producing a good is zero. This assumption serves to simplify the analysis and holds to a very good approximation for products whose total costs are mainly frontloaded by the required R\&D expenditures, but that are relatively cheap to produce (at a small marginal cost) in the commercialization phase, such as pharmaceuticals or computer software.

The innovation phase and the commercialization phase are now discussed in turn, starting with the latter.

\subsection{Product Commercialization}

The firms' best experimental outcomes define their respective quality levels, $q_{1}$ and $q_{2}$. Let $q_{H}=$ $\max \left\{q_{1}, q_{2}\right\}$ be the quality of the "flagship" top performer and $q_{L}=\min \left\{q_{1}, q_{2}\right\}$ be the "generic" runnerup quality. The heterogeneous quality levels offered on the product market, together with the firms' chosen price levels, $p_{H}$ and $p_{L}$, segment the consumer base.

Proposition 1. Given the qualities $q_{H}, q_{L}$ (with $0<$ $q_{L}<q_{H} \leq 1$ ) and prices $p_{H}, p_{L}$ (with $0 \leq p_{L}<$ $\left.p_{H} \leq 1\right)$, consumers with types in $\Theta_{H}=\left[\theta_{1}, 1\right]$ purchase the flagship product (of quality $q_{H}$ ), those with types in $\Theta_{L}=\left[\theta_{0}, \theta_{1}\right]$ purchase the generic product (of quality $q_{L}$ ), and the remaining consumers with types in $\Theta_{0}=\left[0, \theta_{0}\right]$ do not purchase at all, where $\theta_{0}=$ $p_{L} / q_{L} \in \Theta_{0} \cap \Theta_{L}$ and $\theta_{1}=\left(p_{H}-p_{L}\right) /\left(q_{H}-q_{L}\right) \in$ $\Theta_{L} \cap \Theta_{H}$ are "marginal" types..$^{8}$

Proof. Let firm $H$ be the firm offering the flagship product of quality $q_{H}$ and firm $L$ be the firm offering the generic product of quality $q_{L}$. The marginal consumer who is indifferent between choosing the product of quality $q_{H}$ and the product of quality $q_{L}$ is therefore of type $\theta_{1}$ such that $u\left(p_{H}, q_{H} ; \theta_{1}\right)=u\left(p_{L}, q_{L} ; \theta_{1}\right)$, so $\theta_{1}=\left(p_{H}-p_{L}\right) /\left(q_{H}-q_{L}\right)$ as claimed. Similarly, the marginal consumer indifferent between purchasing nothing and buying the generic product is such that $0=u\left(0,0 ; \theta_{0}\right)=u\left(p_{L}, q_{L} ; \theta_{0}\right)$, whence $\theta_{0}=p_{L} / q_{L}$, which concludes our proof.

The market segments (see Fig. 2) imply the firms' profits as a function of their pricing decisions, which in turn allows them to anticipate each other's best responses. The intersection of the firms' best responses to the opponents' price choices yields a unique Nashequilibrium strategy profile. The resulting equilibrium prices $p_{H}^{*}$ and $p_{L}^{*}$, which depend on the realized performance levels $q_{H}$ and $q_{L}$, can be considered as a fairly robust prediction of market prices at the productcommercialization stage.

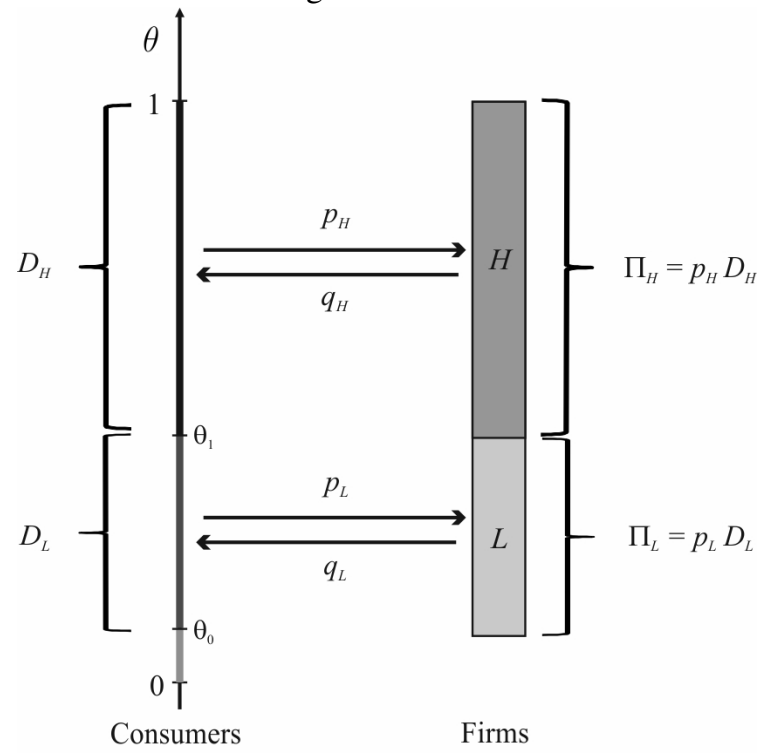

Figure 2: Market segments with demands $D_{H}, D_{L}$.

Proposition 2. The (profit-maximizing) firms' Nashequilibrium prices are

$$
p_{H}^{*}=\frac{2 q_{H}\left(q_{H}-q_{L}\right)}{4 q_{H}-q_{L}}
$$

and

$$
p_{L}^{*}=\frac{q_{L}\left(q_{H}-q_{L}\right)}{4 q_{H}-q_{L}},
$$

given the realized qualities $q_{L}, q_{H}$ (with $0 \leq q_{L}<$ $\left.q_{H} \leq 1\right)$.

Proof. Given the market segments in Prop. 1] (defined by $\theta_{0}$ and $\left.\theta_{1}\right)$, firm $H$ 's profit is $\Pi_{H}=\left(1-\theta_{1}\right) p_{H}$ and firm $L$ 's profit is $\Pi_{L}=\left(\theta_{1}-\theta_{0}\right) p_{L}$. Thus, the firms' best-response functions are

$b_{H}\left(p_{L}\right)=\frac{\left(q_{H}-q_{L}\right)+p_{L}}{2}$, and $b_{L}\left(p_{H}\right)=\frac{p_{H} q_{L}}{2 q_{H}}$,

which implies the Nash-equilibrium prices

$$
p_{H}^{*}=b_{H}\left(b_{L}\left(p_{H}^{*}\right)\right)=\frac{2 q_{H}\left(q_{H}-q_{L}\right)}{4 q_{H}-q_{L}},
$$

and

$$
p_{L}^{*}=b_{L}\left(b_{H}\left(p_{L}^{*}\right)\right)=\frac{q_{L}\left(q_{H}-q_{L}\right)}{4 q_{H}-q_{L}},
$$

as claimed.

Proposition 3. The firms' Nash-equilibrium profits are

$$
\Pi_{H}^{*}\left(q_{H}, q_{L}\right)=\frac{4 q_{H}^{2}\left(q_{H}-q_{L}\right)}{\left(4 q_{H}-q_{L}\right)^{2}},
$$

\footnotetext{
${ }^{8}$ Marginal types are indifferent between two purchase decisions; their overall likelihood of occurrence in the type space $\Theta$ vanishes.
} 
and

$$
\Pi_{L}^{*}\left(q_{H}, q_{L}\right)=\frac{q_{H} q_{L}\left(q_{H}-q_{L}\right)}{\left(4 q_{H}-q_{L}\right)^{2}},
$$

at time $t=1$, given the realized qualities $q_{L}, q_{H}$ (with $0 \leq q_{L}<q_{H} \leq 1$ ).

Proof. The marginal consumers in equilibrium (denoted by $\theta_{0}=\theta_{0}^{*}$ and $\theta_{1}=\theta_{1}^{*}$ ) are obtained by combining the results in Prop. 1 and Prop.2.

$$
\theta_{1}^{*}=\frac{2 q_{H}-q_{L}}{4 q_{H}-q_{L}} \in(0,1)
$$

and

$$
\theta_{0}^{*}=\frac{q_{H}-q_{L}}{4 q_{H}-q_{L}} \in\left(0, \theta_{1}^{*}\right) .
$$

This implies the given expressions for the firms' equilibrium profits at time $t=1$.

Remark 1. The firms' pricing decisions are strategic complements, as their best-response functions (see $b_{H}$ and $b_{L}$ in the proof of Prop. 2) are increasing: each firm prefers to set a higher price as the other firm increases its price. As a result, there would be an advantage to move second when choosing a price. That is, the ability to commit to a price before the other firm is not desirable in this price-setting game. Each firm would want to adjust its price after the other firm has moved. Hence, the Nash-equilibrium outcome of the simultaneous-move game as given in the previous results can be considered as fairly robust with respect to additional strategic actions the firms might take in order to influence the pricing decisions. Here, given the Nashequilibrium prices $p_{H}^{*}$ and $p_{L}^{*}$, no firm has a unilateral incentive to change its price.

\subsection{Noncooperative Innovation}

To determine the level of innovation in a noncooperative setting we need to answer the question of how many experiments $n^{*}(c)$ would each firm want to conduct at time $t=0$ in equilibrium? The answer generally depends on whether the firm with the higher-performance product can claim patent protection and exercise the right to exclude the other firm, thus effectively limiting $q_{L}$ to zero?

The probability that the outcome of the best of $n$ experiments does not exceed $x \in[0,1]$ is $x^{n}$. Thus, if firm $j$ conducts $\nu$ experiments and firm $i \neq j$ conducts $n$ experiments, the probability of firm $i$ winning the innovation race with a higher-quality product is

$$
P\left(\max \left\{\tilde{x}_{1}, \ldots, \tilde{x}_{n}\right\} \geq \max \left\{\tilde{y}_{1}, \ldots, \tilde{y}_{\nu}\right\}\right)
$$

$$
=\int_{0}^{1} \nu y^{\nu-1}\left(\int_{y}^{1} n x^{n-1} d x\right) d y=\frac{n}{n+\nu} .
$$

With patent protection, its expected payoff becomes ${ }^{10}$

$$
\bar{\Pi}_{i}^{*}=\frac{1}{4} \int_{0}^{1} \nu y^{\nu-1}\left(\int_{y}^{1} n x^{n} d x\right) d y-c n,
$$

which is equal to

$$
\frac{n}{4(n+1)} \int_{0}^{1} \nu y^{\nu-1}\left(1-y^{n+1}\right) d y-c n,
$$

or, more simply put:

$$
\bar{\Pi}_{i}^{*}=\frac{n}{4(n+\nu+1)}-c n .
$$

Proposition 4. With patent protection, each firm $i \in$ $\{1,2\}$ conducts in equilibrium 11

$$
n_{i}^{*}(c)=\left[\frac{1+\sqrt{1+32 c}}{32 c}-\frac{1}{2}\right]_{+}
$$

experiments.

Proof. Maximizing $\bar{\Pi}_{i}^{*}$ with respect to $n$ leads to the first-order necessary optimality condition

$$
\frac{\nu+1}{4(n+\nu+1)^{2}}-c=0,
$$

and, similarly, maximizing $\bar{\Pi}_{j}^{*}$ with respect to $\nu$ leads to the first-order necessary optimality condition

$$
\frac{n+1}{4(n+\nu+1)^{2}}-c=0,
$$

provided $c$ is small enough (so as to allow for a nonnegative solution). The symmetric solution to the preceding two equations (including the possibility of a corner solution with zero innovation),

$$
n_{i}^{*}(c)=n_{j}^{*}(c)=\left[\frac{1+\sqrt{1+32 c}}{32 c}-\frac{1}{2}\right]_{+},
$$

for $i, j \in\{1,2\}$ with $i \neq j$, constitutes the unique Nash equilibrium of the firms' simultaneous-move "innovation game."

Without patent protection, on the other hand, firm $i$ 's expected payoff is

$$
\hat{\Pi}_{i}^{*}=n \nu \int_{[0,1]^{2}} x^{n-1} y^{\nu-1} \pi^{*}(x, y) d(x, y)-c n,
$$

where the commercialization profits, as a function of the realized performance tuple $(x, y)$, is 12

$$
\pi^{*}(x, y)=\Pi_{H}^{*}(x, y) \mathbf{1}_{\{x>y\}}+\Pi_{L}^{*}(y, x) \mathbf{1}_{\{x \leq y\}},
$$

and where $\mathbf{1}_{\{\cdot\}}$ denotes the indicator function.

\footnotetext{
${ }^{9}$ Instead of forcing $q_{L}=0$, an alternative modeling scenario might limit the low quality $q_{L}$ to a positive value, representing the quality of a freely available generic product, somewhat reducing the incentives to win the patent race for the innovators.

${ }^{10}$ Here we use the fact that by Prop. $3 \Pi_{H}^{*}(x, 0)=x / 4$ and $\Pi_{L}^{*}(y, 0)=0$, for all $(x, y) \in[0,1]^{2}$.

${ }^{11}$ For any real number $\alpha$, the expression $[\alpha]_{+} \triangleq \max \{0, \alpha\}$ denotes the positive part of $\alpha$.

${ }^{12}$ The definition of $\pi^{*}$ along the diagonal $x=y$ of the square $[0,1]^{2}$ does not affect the value of $\hat{\Pi}_{i}^{*}$.
} 
Proposition 5. Without patent protection, each firm $i \in\{1,2\}$ conducts in equilibrium

$\hat{n}_{i}^{*}(c)=\left[\frac{c}{\int_{[0,1]^{2}}(x y)^{\hat{n}_{i}^{*}(c)-1} \pi^{*}(x, y)\left(1+\hat{n}_{i}^{*}(c) \ln (x)\right) d(x, y)}\right]_{+}$

experiments 13

Proof. Maximizing firm $i$ 's expected commercialization payoff $\hat{\Pi}_{i}^{*}$ with respect to $n$, leads to the first-order optimality condition (satisfied at any interior optimum where $\left.\hat{n}_{i}^{*}(c)>0\right)$,

$\int_{[0,1]^{2}}(x y)^{\hat{n}_{i}^{*}(c)-1} \pi^{*}(x, y)\left(1+\hat{n}_{i}^{*}(c) \ln (x)\right) d(x, y)=\frac{c}{\hat{n}_{i}^{*}(c)}$,

where we have (by symmetry) replaced $\nu$ with $\hat{n}_{i}^{*}(c)$. This condition is equivalent to the claimed relation. The relation in footnote 13 is obtained from that same condition by separating $\hat{n}_{i}^{*}(c)$ from the integral expressions as much as possible, leading to a quadratic equation.

There are two conflicting effects when comparing the situation without patent protection to the situation with patent protection: without patent protection, conditional on obtaining the better product a firm's expected payoffs are lower, and conditional on losing the innovation race the firm's expected payoffs are higher. In either case, the value of winning the patent race decreases. Thus, one could expect a decrease in the equilibrium experimentation levels which are then closer to socially optimal levels. All else equal, the firms ex post prefer to have patent protection for the best innovation. This regime clearly provides strong incentives for privatesector inventive activity.

\subsection{Collaborative Innovation}

If the firms cooperate at the R\&D stage and run their experiments jointly based on a profit-sharing agreement, what would be the optimal number of experiments to run? To answer this question, we assume that the firms maximize joint profits, which would be the case regardless of patent protection 14

Proposition 6. Given the qualities $q_{H}, q_{L}$ (with $0<$ $q_{L}<q_{H} \leq 1$ ), the firms' joint profit is maximized at the "collaborative" price levels $p_{H}^{* *}=q_{H} / 2$ and $p_{L}^{* *}=$ $q_{L} / 2$ for the flagship product and the generic product, respectively. The firms' optimal collaborative profit is $\Pi^{* *}\left(q_{L}, q_{H}\right)=q_{H} / 4$.
Proof. Note first that the firms' joint profit is

$$
\Pi=\Pi_{H}+\Pi_{L}=\left(1-\theta_{1}\right) p_{H}+\left(\theta_{1}-\theta_{0}\right) p_{L},
$$

with the marginal types $\theta_{0}, \theta_{1}$ defining the market segments as in Prop. 11. To maximize $\Pi$ with respect to the price tuple $\left(p_{H}, p_{L}\right)$, the first-order necessary optimality conditions are

$$
\begin{aligned}
\frac{\partial \Pi}{\partial p_{H}} & =1-2\left(\frac{p_{H}-p_{L}}{q_{H}-q_{L}}\right)=0 \\
\frac{\partial \Pi}{\partial p_{L}} & =2\left(\frac{p_{H} q_{L}-p_{L} q_{H}}{\left(q_{H}-q_{L}\right) q_{L}}\right)=0
\end{aligned}
$$

By the joint concavity of $\Pi$ with respect to $\left(p_{H}, p_{L}\right) 15$ the preceding optimality conditions yield the unique maximizer $\left(p_{H}^{* *}, p_{L}^{* *}\right)$ as specified. The collaborative joint profit obtains by substituting the optimal collaborative prices in the firms' joint profit $\Pi$.

Prop. 6 implies the marginal consumer types $\theta_{0}^{* *}=$ $1 / 2$ and $\theta_{1}^{* *}=1 / 2$. In other words, when acting jointly it is best for the firms to restrict product variety and commercialize only the top-performance flagship product. This determines the incentives for the firms' collaborative inventive activity.

Proposition 7. The firms' optimal number of collaborative experiments is

$$
n^{* *}(c)=\left[\frac{1}{2 \sqrt{c}}-1\right]_{+},
$$

for all $c>0$.

Proof. Given the firms' optimal collaborative profit $\Pi^{* *}(x, y)=x / 4$ in Prop. 6 for a flagship quality $x \in[0,1]$, the optimal number $n^{* *}(c)$ of joint experiments maximizes their expected payoff at the beginning of the innovation phase:

$$
n^{* *}(c) \in \arg \max _{n \geq 0}\left\{\frac{1}{4} \int_{0}^{1} n x^{n} d x-c n\right\} .
$$

The preceding optimization problem is equivalent to

$$
n^{* *}(c) \in \arg \max _{n \geq 0}\left\{\frac{n}{4(n+1)}-c n\right\} .
$$

The solution can easily be obtained in closed form and is as specified in Prop.7.

The firms' inventive activity is positive if and only if the (positive) cost of experimentation is sufficiently small, so $c<1 / 4$.

\footnotetext{
${ }^{13}$ The implicit expression is equivalent to $\hat{n}_{i}^{*}(c)=\left(\sqrt{A_{i}^{2}+4 B_{i} c}-A_{i}\right) / 2 B_{i}$, where $A_{i} \triangleq \int_{[0,1]^{2}}(x y)^{\hat{n}_{i}^{*}(c)-1} \pi^{*}(x, y) d(x, y)$ and $B_{i} \triangleq \int_{[0,1]^{2}}(x y)^{\hat{n}_{i}^{*}(c)-1} \pi^{*}(x, y) \ln (x) d(x, y)$ depend on $\hat{n}_{i}^{*}(c)>0$, defining a fixed-point problem, for $i \in\{1,2\}$.

${ }^{14}$ Intellectual property protection for the group of firms could be obtained in the form of a joint patent, or suitable cross-licensing agreements may be put in place. None of the internal transfer agreements that may exist would a priori impact the firms' joint profit expectations.

${ }^{15}$ The trace of the Hessian is negative (equal to $-2\left(1+\left(q_{H} / q_{L}\right)\right) /\left(q_{H}-q_{L}\right)$ ) and its determinant is positive (equal to $4 /\left(\left(q_{H}-q_{L}\right) q_{L}\right)$ ), indicating that both of its eigenvalues must be negative, thus establishing joint concavity of $\Pi$ in $\left(p_{H}, p_{L}\right)$.
} 


\section{Benchmark: Social Optimality}

Given that the firms' production cost is negligible compared to the product pricing, the social welfare amounts simply to the gross consumer surplus, as the monetary transfers between consumers and companies are irrelevant for the sum of benefits in the economy. Thus, given the qualities $q_{H}, q_{L}$ (with $0<q_{L}<q_{H} \leq 1$ ) total welfare is

$$
W\left(q_{H}, q_{L}\right)=q_{H} \int_{\theta_{1}}^{1} \theta d \theta+q_{L} \int_{\theta_{0}}^{\theta_{1}} \theta d \theta
$$

where the marginal types $\theta_{0}, \theta_{1}$ determine the demand segments and are given in Prop. 1 .

\subsection{First-Best Pricing}

While the magnitude of the monetary transfers from consumers to producers does not affect the welfare in the economy, the overall price and performance levels does affect the consumers' gross surplus and thus also the social planner's objective function. A socially optimal commercialization strategy would apply "firstbest" (i.e., welfare-maximizing) prices $p_{H}^{\mathrm{FB}}\left(q_{H}, q_{L}\right)$ and $p_{L}^{\mathrm{FB}}\left(q_{H}, q_{L}\right)$.

Proposition 8. The (socially optimal) first-best prices are

$$
p_{H}^{F B}=p_{L}^{F B}=0,
$$

independent of the realized qualities.

Proof. Clearly, the gross consumer surplus is maximal if all consumers on the market consume the topperformance product of quality $q_{H}$. This outcome can be implemented if $\theta_{0}=\theta_{1}=0$, which holds when both prices vanish.

This implies $W^{\mathrm{FB}}=q_{H} / 2$. Since marginal production costs are approximately zero (by hypothesis), it is not surprising that the welfare-maximizing prices in the product commercialization phase are also zero. However, such prices would not allow the firms to make up their innovation cost, and in fact altogether destroy their incentives to create new products, as any positive $R \& D$ expenditures could not be recouped.

\subsection{First-Best Experimentation}

Given the implementation of a social optimum in the commercialization phase, effectively maximizing gross consumer surplus, the question arises as to a social planner's incentives for innovation.

Proposition 9. The (socially optimal) first-best number of experiments is

$$
n^{F B}(c)=\left[\frac{1}{\sqrt{2 c}}-1\right]_{+},
$$

for all $c>0$.

Proof. Since for any realized flagship quality $x \in[0,1]$, the optimal social welfare is $W^{\mathrm{FB}}=x / 2$, analogous to the proof of Prop. 7 the socially optimal number of experiments $n^{\mathrm{FB}}(c)$ solves

$$
\max _{n \geq 0}\left\{\frac{1}{2} \int_{0}^{1} n x^{n} d x-c n\right\},
$$

or equivalently,

$$
\max _{n \geq 0}\left\{\frac{n}{2(n+1)}-c n\right\},
$$

which implies the given closed-form expression, for all $c>0$.

The firms' rent-seeking behavior, when they use experimentation to obtain an advantage in the product market, leads to socially inefficiently high innovation. In other words, many high-technology products may not be the result of the firms' responsiveness to real consumer needs but rather a consequence of a patent race that promises each firm a chance of obtaining supranormal rents.

\section{Comparison}

In the noncooperative regime, let $n^{*}(c)=n_{1}^{*}(c)+n_{2}^{*}(c)$ be the firms' inventive activity with patent protection (see Prop. 4), and let $\hat{n}^{*}(c)=\hat{n}_{1}^{*}(c)+\hat{n}_{2}^{*}(c)$ denote their inventive activity without patent protection (see Prop. 5p. When the firms collaborate, their joint inventive activity is $n^{* *}(c)$ (see Prop. 7), and finally, the socially optimal (or first-best) inventive activity is given by $n^{\mathrm{FB}}(c)$ (see Prop. 9 ). The expected top-performance product quality in the market is strictly monotonic in the total experimentation the firms carry out. The latter corresponds to their joint inventive activity in each of the four different regimes.

Proposition 10. (i) $\left(c-c_{0}\right)\left(n^{F B}(c)-n^{*}(c)\right)>0$, for all $c \in(0,1 / 2) \backslash\left\{c_{0}\right\}$ where $c_{0}=1 / 18$. (ii) $\min \left\{n^{F B}(c), n^{* *}(c)\right\}>\max \left\{\hat{n}^{*}(c), n^{* *}(c)\right\}$, for all $c \in(0,1 / 4)$. (iii) $n^{* *}(c)>\hat{n}^{*}(c)$ if any only if $c \in$ $\left(0, c_{1}\right) \cup\left(c_{2}, 1 / 4\right)$, where $c_{1} \approx 0.002$ and $c_{2} \approx 0.086$.

Proof. (i) From Prop. 4 and Prop. 9 we obtain that $n^{\mathrm{FB}}(c)>n^{*}(c)$ if and only if

$$
\left[\frac{1}{\sqrt{2 c}}-1\right]_{+}>\left[\frac{1+\sqrt{1+32 c}}{16 c}-1\right]_{+},
$$

which (for $c \in(0,1 / 2)$ ) is equivalent to:

$$
c>c_{0}=\frac{1}{18} \approx 0.0556 .
$$

Parts (ii) and (iii) follow from an exhaustive numerical inspection. 
Prop. 10 states that the socially optimal inventive activity exceeds the privately optimal inventive activity for larger values of the experimentation cost (i.e., when $c>1 / 18$ ); see Fig. 3. Otherwise, private firms with patent protection invest more in research and development than what may be socially optimal, but the quality outcomes in that case are the highest. Furthermore, the result implies that collaborative inventive activity with patent protection is (when nonzero) always smaller than noncollaborative inventive activity with patent protection. It is even smaller than noncollaborative inventive activity without patent protection for small experimentation costs (i.e., $c<c_{1} \approx 0.002$ ) and for larger experimentation costs (i.e., $c>c_{2} \approx 0.086$ ); see Fig. 4 .

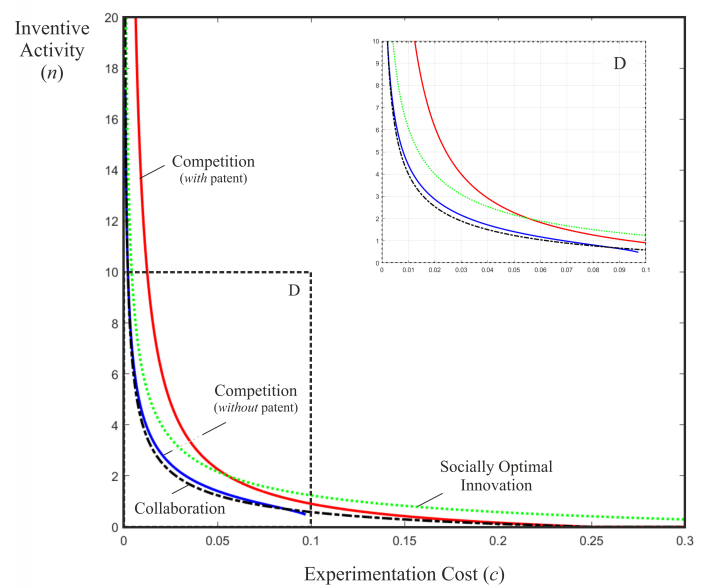

Figure 3: Comparison of the inventive activity under competition (with and without patent protection), collaboration, and from a social planner's perspective, as a function of experimentation cost.

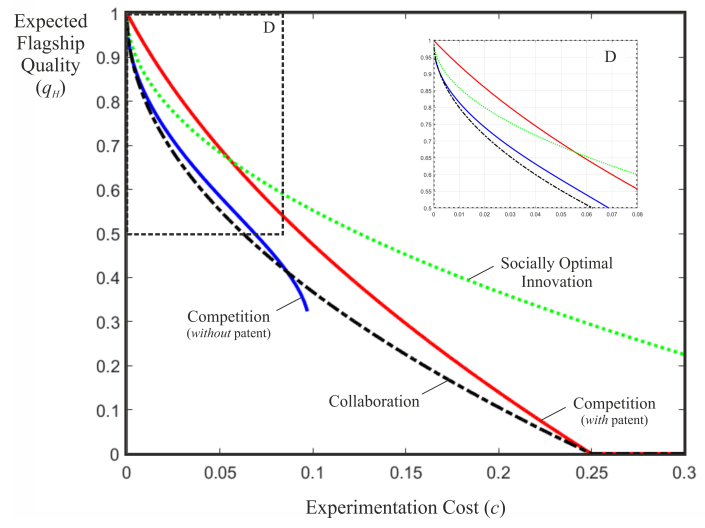

Figure 4: Comparison of the expected top-performance quality under competition (with and without patent protection), collaboration, and from a social planner's perspective, as a function of experimentation cost.

\section{Conclusion}

Using a simple two-stage model we have shown that short of a social planner imposing a welfare-maximizing solution, noncooperative research with patent protection of the best-performing invention leads to the strongest R\&D incentives, and thus also to the best expected output in terms of product quality. When experimentation costs are sufficiently small, the resulting private incentives lead to inventive activity that exceeds the socially optimal efforts, which in turn implies exceedingly highquality products. It is important to note that in reaching these findings we have excluded all the standard out-ofthe-box explanations, which must therefore be essential to obtain an economically grounded rationale for collaborative research. For example, if collaboration can reduce the cost of experimentation (e.g., through economies of specialization with modular subsystems; see footnote 3), then there exists a cost reduction at which the collaborative effort catches up to the noncooperative solution. However, it can easily be shown that the required relative cost reduction from cooperation approaches $100 \%$ as experimentation costs fall. ${ }^{16}$ This generically disqualifies the cost-reduction argument for collaborative research, at least in environments where experiments can be conducted at relatively low cost.

\section{References}

[1] ALLEN, R.C. (1983) "Collective Invention," Journal of Economic Behavior and Organization, Vol. 4, No. 1, pp. 1-24.

[2] Axelrod, R.M. (1984) The Evolution of Cooperation, Basic Books, New York, NY.

[3] Baldwin, C.Y., Clark, K.B. (2000) Design Rules: The Power of Modularity, MIT Press, Cambridge, MA.

[4] Baldwin, C., von Hippel, E. (2011) "Modeling a Paradigm Shift: From Producer Innovation to User and Open Collaborative Innovation," Organization Science, Vol. 22, No. 6, pp. 1399-1417.

[5] Chesbrough, H. (2003) Open Innovation: The New Imperative for Creating and Profiting from Technology, Harvard Business School Press, Cambridge, MA.

[6] Coase, R.H. (1960) "The Problem of Social Cost," Journal of Law and Economics, Vol. 3, pp. 1-44.

[7] Czarnitzki, D., Ebersberger, B., Fier, A. (2007) "The Relationship between R\&D Cooperation, Subsidies and R\&D Performance: Empirical Evidence from Finland and Germany," Journal of

\footnotetext{
${ }^{16}$ Using the findings in Props. 4 and 7 one obtains that $n^{* *}(\hat{c})=n^{*}(c)$ if $\hat{c}=c-\Delta$, where the required absolute cost reduction $\Delta$ (which depends on $c)$ implies the relative reduction $\Delta / c=(1+\sqrt{1+32 c}-16 c) /(1+\sqrt{1+32 c}+16 c)$ for all $c \in(0,1 / 4)$, thus approaching a required $100 \%$ relative cost reduction for $c \rightarrow 0^{+}$.
} 
Applied Econometrics, Vol. 22, No. 7, pp. 13471366.

[8] Feldman, M.P. (1994) "Knowledge Complementarity and Innovation," Small Business Economics, Vol. 6, pp. 363-372.

[9] Fleming, S. (2020) "The Great Coronavirus Collaboration and the Future of Drug Discovery," Forbes, June 5 (accessed on July 14, 2020).

[10] Fjeldstad, Ø.D., Snow, C.C., Miles, R.E., LETTL, C. (2012) "The Architecture of Collaboration," Strategic Management Journal, Vol. 33, No. 6, pp. 734-750.

[11] FORAY, D. (2004) The Economics of Knowledge, MIT Press, Cambridge, MA.

[12] Friedman, J.W. (1971) “A Non-Cooperative Equilibrium for Supergames," Review of Economic Studies, Vol. 38, No. 1, pp. 1-12.

[13] Fudenberg, D., Maskin, E. (1986) "The Folk Theorem in Repeated Games with Discounting or with Incomplete Information," Econometrica, Vol. 54, No. 3, pp. 533-554.

[14] VON HipPEL, E. (1987) "Cooperation Between Rivals: Informal Know-How Trading," Research Policy, Vol. 16, No. 6, pp. 291-302.

[15] MowerY, D.C. (1998) "Collaborative R\&D: How Effective Is It?" Issues in Science and Technology, Vol. 15, No. 1 (Fall 1998) (accessed on July 14, 2020).
[16] Muss A, M., Rosen, S. (1978) "Monopoly and Product Quality," Journal of Economic Theory, Vol. 18, No. 2, pp. 301-317.

[17] Nelson, R.R. (1959) "The Simple Economics of Basic Scientific Research," Journal of Political Economy, Vol. 67, No. 3, pp. 297-306.

[18] Reinganum, J.F. (1989) "The Timing of Innovation: Research, Development, and Diffusion," in: Schmalensee, R., Willig, R.D. (Eds.) Handbook of Industrial Organization, Vol. I, North Holland, Amsterdam, NL.

[19] Rosenkopf, L., Almeida, P. (2003) “Overcoming Local Search Through Alliances and Mobility," Management Science, Vol. 49, No. 6, pp. 751766.

[20] SChumpeter, J.A. (1934) The Theory of Economic Development: An Inquiry into Profits, Capital, Credit, Interest, and the Business Cycle, Harvard University Press, Cambridge, MA.

[21] TeEce, D.J. (1986) "Profiting from Technological Innovation: Implications for Integration, Collaboration, Licensing and Public Policy," Research Policy, Vol. 15, No. 6, pp. 285-305.

[22] Weitzman, M.L. (1979) "Optimal Search for the Best Alternative," Econometrica, Vol. 47, No. 3, pp. 641-654.

[23] West, J., Bogers, M. (2013) "Leveraging External Sources of Innovation: A Review of Research on Open Innovation," Journal of Product Innovation Management, Vol. 31, No. 4, pp. 814831 